\title{
REDUCED QUALITY OF LIFE IN PATIENTS WITH NON-EROSIVE GASTROESOPHAGEAL REFLUX DISEASE
}

\author{
Márcia da Silva Vargas ${ }^{1,2}$, Valesca Dall'Alba ${ }^{1,2,3}$, \\ Sergio Gabriel Silva de Barros ${ }^{1}$, Renato Borges Fagundes ${ }^{1,4}$
}

\begin{abstract}
Introduction: Gastroesophageal reflux disease (GERD) is a highly prevalent condition in the Western world. It is a frequent cause of medical appointments and has a high impact on quality of life (QOL). This study aimed to assess health-related quality of life (HQ-QOL) of patients with non-erosive gastroesophageal disease (NERD) and compare their scores with the scores of patients with GERD symptoms and non-pathological acid reflux (non-NERD).
\end{abstract}

Methods: We studied 42 patients with GERD symptoms-21 with positive pHmetry for acid reflux (NERD group) and 21 with negative pHmetry for acid reflux (non-NERD group). We enrolled patients matched by age and gender. Patient inclusion criteria were based on clinical and endoscopic findings and pHmetry. All other major diseases having an impact on QOL were excluded as well as patients in regular use of proton pump inhibitors, prokinetics, histamine-2 receptor antagonists and anti-depressants. All subjects were asked to fill in a validated translation of the SF-36 questionnaire. We described scores trough median and interquartile range (IQR) and assessed the significance of the comparisons through Mann-Whitney test and chi-square test or Student's $t$-test when appropriate.

Results: We found no significant differences in the eight domains of SF-36 between the two groups.

Conclusion: QOL of patients with GERD symptoms was equivalent, regardless of acid reflux at pHmetry.

Keywords: SF-36; quality of life; gastroesophageal reflux; pHmetry

Gastroesophageal reflux disease (GERD) is a complex, chronic, and relapsing condition with morbidity and potential for complications. Montreal consensus defines GERD as "[...] a condition which develops when the reflux of stomach contents causes troublesome symptoms and/or complications"1:5. GERD can be classified as erosive esophagitis (EE) or non-erosive reflux disease (NERD). EE is defined as esophageal mucosal lesions at upper gastrointestinal (GI) endoscopy, while NERD is characterized by typical symptoms (heartburn plus acid regurgitation) and no changes at endoscopy ${ }^{2}$. Patients with frequent heartburn have a negative impact on their quality of life $(\mathrm{QOL})^{3}$.

The traditional way of assessing health changes in patients is very often focused on objective clinical or biological tests. Whereas these tests offer information about pathological processes, it is impossible to separate the disease itself from the individual's personal point of view regarding their wellbeing and social perspective. One way to assess this aspect is to measure their QOL ${ }^{4}$.

Our aim was to compare health-related quality of life (HR-QOL) of patients with GERD symptoms and non-erosive gastroesophageal disease (NERD) with patients with non-pathological reflux at $\mathrm{pH}$ esophageal monitoring.
Clin Biomed Res. 2017;37(2):59-62

1 Post-graduate Program: Science in Gastroenterology, Medical School, Universidade Federal do Rio Grande do Sul (UFRGS). Porto Alegre, RS, Brazil.

2 Nutrition Division, Hospital de Clínicas Porto Alegre. Porto Alegre, RS, Brazil.

3 Department of Nutrition, Medical School, Universidade Federal do Rio Grande do Sul (UFRGS). Porto Alegre, RS, Brazil.

4 Department of Medical Clinic, Universidade Federal de Santa Maria (UFSM). Santa Maria, RS, Brazil.

Corresponding author: Márcia da Silva Vargas mvargas@hcpa.edu.br Hospital de Clínicas de Porto Alegre Rua Ramiro Barcelos, 2350. 90035-903, Porto Alegre, RS, Brazil. 


\section{METHODS}

We recruited 57 adult patients (over 18 years old) with GERD symptoms and normal esophageal mucosa at upper $\mathrm{Gl}$ endoscopy. Of those, we included in this study 42 adult patients with GERD symptoms and normal esophageal mucosa at upper Gl endoscopy, from November of 2004 to August of 2005. Patients were divided into two groups according to pHmetry results: NERD and non-NERD. NERD group included patients with abnormal acid reflux at pHmetry. non-NERD group encompassed patients with normal pHmetry. We excluded illiterate patients as well as patients in regular use of pump proton inhibitors, prokinetics, histamine-2 receptor antagonists, and anti-depressants. All patients showed typical symptoms of GERD, such as heartburn and acid regurgitation, and some atypical symptoms, such as chest pain, swallowing difficulties, and pharyngeal globus. They did not show symptoms of dyspepsia syndrome. We did not include patients with chronic disease that could affect QOL adversely, such as cardiovascular disease, chronic kidney disease, obstructive pulmonary disease, cirrhosis, rheumatologic diseases, and any history of cancer.

We asked the patients to fill in a SF-36 questionnaire validated for Portuguese ${ }^{5}$. The SF-36 questionnaire measures generic QOL as well as health status in eight domains: vitality, physical functioning, bodily pain, general health perceptions, physical role functioning, emotional role functioning, mental health, and social functioning. Two summary scores were calculated based on subjects' responses: physical health $(\mathrm{PH})$ score and mental health (MH) score. SF-36 scores range from 0 to 100 in each dimension and in summary scales, with higher scores indicating better $\mathrm{QOL}^{6}$.

Data were tabulated in Microsoft Excel and then analyzed using SPSS version 18 . We described categorical variables (gender and symptoms) through absolute and relative frequencies. Age was described through mean and standard deviation. SF-36 domain scores were described through median and interquartile range (IQR). Significance was assessed through Student's $t$-test, qui-square test, and Mann-Whitney test when appropriate. We considered $p$-values less than 0.05 as significant.

The present study complied with the standards of Helsinki Declaration. The Institutional Review Board of our institution reviewed and approved our protocol. All patients signed an informed consent form before enrollment in the study.

\section{RESULTS}

We excluded 15 patients from the study-five patients did not accomplish esophageal $\mathrm{pH}$ monitoring and 10 did not return the questionnaire. Therefore, we analyzed data from 42 patients. Each group included 15 women and six men. Mean age was $47.5( \pm 11.9)$ in the NERD group and $43.9( \pm 13.3)$ in the non-NERD group, with no significant difference $(p=0.366)$.

Twenty-one (50\%) patients had NERD. There were no statistically significant differences in the standardized scores of SF-36 domains between NERD and non-NERD patients. Table 1 shows data comparing the scores of SF-36 domains between NERD and non-NERD patients.

\section{DISCUSSION}

With the aim of studying QOL in patients with GERD symptoms, mainly heartburn and acid regurgitation, we found no significant differences in any domain of the SF-36 questionnaire among patients who presented positive or negative pHmetry for acid reflux.

GERD is a common disease with lasting symptoms leading to a chronic condition with impact on QOL. Even though heartburn is the most common symptom, there is no evidence whether its severity correlated with the degree of injury in esophageal mucosa ${ }^{7}$. Similarly, we did not find a significant association between discomfort perception and presence or absence of pathological acid reflux detected by pHmetry in our patients. In the present study, we evaluated patients who had typical and atypical symptoms, but their main complaint was heartburn, which was equally distributed among those with and without pathological acid reflux.

Esophageal mucosa damage and clinical symptoms have a complex pathogenesis, and patient perception is a subjective issue linked to the complex phenomenon of visceral sensations. Patients with no relationship between symptoms and acid reflux at pHmetry presented a high level of anxiety ${ }^{8}$.

NERD patients represent up to $60 \%$ of all patients with reflux symptoms, but the mechanisms involved in the pathogenesis of NERD are complex and multifactorial ${ }^{9}$. The non-NERD patients in our sample could be included in the following categories: sensitive esophagus (to acid and non-acid reflux) or functional heartburn. Presentation of esophageal hypersensitivity and GERD may be the same, and pHmetry may show reflux symptoms related to normal acid exposure ${ }^{9}$. Since our non-NERD patients did not present symptoms related to the events of acid reflux, we can rule out acid hypersensitivity in those patients. $\mathrm{pH}$-impedance monitoring is able to detect non-acid reflux, but since we did not perform it, we could not identify those patients in our sample.

When comparing SF-36 domain scores in our patients with NERD and non-NERD, we observed no difference in any item. This supports the hypothesis 
Table 1: SF-36 domain scores for both groups.

\begin{tabular}{lccccc}
\hline \multicolumn{1}{c}{ Domains } & NERD $\mathbf{n}=\mathbf{2 1}$ & & non-NERD $\mathbf{n}=\mathbf{2 1}$ & & \multirow{2}{*}{$\boldsymbol{p}^{*}$} \\
\cline { 2 - 2 } Functional capacity & $52.9(49.9-55.0)$ & & $50.9(39.4-57.1)$ & & 0.493 \\
Physical aspects & $56.2(38.6-56.2)$ & & $42.1(35.0-56.2)$ & & 0.123 \\
Pain & $51.6(37.3-62.7)$ & & $41.8(37.5-54.2)$ & & 0.196 \\
Overal health status & $55.6(46.2-57.9)$ & & $53.2(43.9-57.9)$ & & 0.577 \\
Vitality & $51.4(45.5-62.1)$ & & $46.7(39.6-55.0)$ & & 0.240 \\
Social aspects & $46.3(29.9-57.1)$ & & $40.9(32.7-54.4)$ & & 1.000 \\
Emotional aspects & $34.2(29.0-55.3)$ & & $44.6(34.3-55.3)$ & & 0.290 \\
Mental health & $48.2(39.1-56.2)$ & & $45.9(34.5-55.0)$ & & 0.504 \\
Physical health & $55.8(44.1-58.5)$ & & $47.8(37.7-57.1)$ & & 0.090 \\
Mental health & $41.6(34.1-54.9)$ & & $44.3(34.6-55.1)$ & & 0.850 \\
\hline
\end{tabular}

*Mann-Whitney test.

that other variables, such as functional disorders (visceral hyperalgesia and allodynia), can also be found in these patients. Our results agree with those from a study that demonstrated that reflux symptom severity and general QOL scores of erosive esophagitis in NERD patients were similar ${ }^{10}$.

The definition of functional heartburn criteria has evolved over the years. Rome II criteria included acid sensitive esophagus in the functional heartburn group. This conception was revised by ROME III and classified as part of the NERD group ${ }^{11}$. Rome IV defined functional heartburn as heartburn with no evidence for GERD, no correlation with reflux symptom, and with a negative response to acid-suppressive therapy ${ }^{12}$.

Little is known about the pathogenesis of functional heartburn. Zerbib et al..$^{13}$ showed no significant difference between functional heartburn patients and controls regarding intercellular esophageal distance. The authors also demonstrated that heartburn might be perceived despite the maintenance of mucosa integrity. Farre et al. also showed that the presence of intercellular esophageal distance alone is not sufficient to generate symptoms, at least in healthy subjects in whom esophageal perfusions of acid and bile were performed ${ }^{14}$. Moreover, we recently showed that the number of total acid and weakly acid refluxes does not differ between functional heartburn and control subjects and is significantly lower than in the two subsets of NERD (pH-positive and HE). Patients with functional heartburn who report heartburn without any correlation with gastroesophageal reflux events seem to be more sensitive to mechanical and chemical stimuli than NERD patients ${ }^{13}$. Further studies are needed to better clarify the mechanisms of symptom generation in patients with gastroesophageal reflux and functional heartburn ${ }^{15}$.

Our study has some limitations. One of them is the small sample, but the equal number and similarity of patients in both groups might provide internal validity to the study, but prevent inferences about the general population. Another possible bias is that the main psychiatric diseases that could affect HR-QOL were not assessed. Therefore, we cannot tell what specific influence psychological variables could have on our results. We believe that the equal number of patients in both groups and their similarity in terms of mental and emotional domains lessened this limitation. We need to replicate this study with a broader sample, controlling for psychological variables and their influence on symptoms to make inferences about the general population.

In conclusion, our study showed impairment of QOL in patients with reflux symptoms regardless of their pHmetry results. Symptom perception is more relevant to patients than the results of diagnostic tests.

\section{Conflicts of interest}

The authors declare no conflicts of interest.

\section{REFERENCES}

1. Vakil N, van Zanten SV, Kahrilas P, Dent J, Jones R, and the Global Consensus Group. The Montreal definition and classification of gastroesophageal reflux disease: a global evidence-based consensus. Am J Gastroenterol. 2006;101(8):1900-
20, quiz 1943. PMid:16928254. http://dx.doi.org/10.1111/j.15720241.2006.00630.x.

2. Lee SW, Chang CS, Lien HC, Peng YC, Wu CY, Yeh HZ. Impact of Overlapping Functional
Gastrointestinal Disorders on the Presentation and Quality of Life of Patients with Erosive Esophagitis and Nonerosive Reflux Disease. Med Princ Pract. 2015;24(5):4915. PMid:26137901. http://dx.doi. org/10.1159/000431370. 
3. Dent J, Brun J, Fendrick AM, Fennerty MB, Janssens J, Kahrilas PJ, et al. An evidence-based appraisal of reflux disease management--the Genval Workshop Report. Gut. 1999;44(Suppl 2):S1-16. PMid:10741335. http:// dx.doi.org/10.1136/gut.44.2008.S1.

4. Higginson IJ, Carr AJ. Measuring quality of life: using quality of life measures in the clinical setting. BMJ. 2001;322(7297):1297-300. PMid:11375237. http://dx.doi. org/10.1136/bmj.322.7297.1297.

5. Fornari F, Gruber AC, Lopes AB, Cecchetti D, Barros SGS. Symptom's questionnaire for gastroesophageal reflux disease. Arq Gastroenterol. 2004;41(4):263-7. PMid:15806272. http://dx.doi.org/10.1590/S000428032004000400012.

6. Lee SW, Lee TY, Lien HC, Yang SS, Yeh HZ, Chang CS. Characteristics of symptom presentation and risk factors in patients with erosive esophagitis and nonerosive reflux disease. Med Princ Pract. 2014;23(5):4604. PMid:25012767. http://dx.doi. org/10.1159/000363661.

7. Tack J, Becher A, Mulligan C, Johnson DA. Systematic review: the burden of disruptive gastro-oesophageal reflux disease on health-related quality of life. Aliment Pharmacol Ther. 2012;35(11):1257-66. PMid:22486579. http://dx.doi.org/10.1111/j.13652036.2012.05086.x.

8. Johnston BT, Lewis SA, Collins JS, McFarland RJ, Love AH. Acid perception in gastro-oesophageal reflux disease is dependent on psychosocial factors. Scand J Gastroenterol. 1995;30(1):15. PMid:7701244. http://dx.doi. org/10.3109/00365529509093228.

9. Patel A, Sayuk GS, Gyawali CP. Parameters on esophageal $\mathrm{pH}$-impedance monitoring that predict outcomes of patients with gastroesophageal reflux disease.

Clin Gastroenterol Hepatol.

2015;13(5):884-91. PMid:25158924. http://dx.doi.org/10.1016/j. cgh.2014.08.029.

10. Lee SW, Lien HC, Lee TY, Yang SS, Yeh HJ, Chang CS. Heartburn and regurgitation have different impacts on life quality of patients with gastroesophageal reflux disease. World J Gastroenterol. 2014;20(34):12277-82. PMid:25232262. http://dx.doi. org/10.3748/wjg.v20.i34.12277.

11. Galmiche JP, Clouse RE, Bálint A, Cook IJ, Kahrilas PJ, Paterson
WG, et al. Functional esophageal disorders. Gastroenterology. 2006;130(5):1459-65. PMid:16678559. http://dx.doi.org/10.1053/j. gastro.2005.08.060.

12. Aziz Q, Fass R, Gyawali CP, Miwa H, Pandolfino JE, Zerbib F. Functional esophageal disorders. Gastroenterology. 2016;150(6):136879. PMid:27144625. http://dx.doi. org/10.1053/j.gastro.2016.02.012.

13. Zerbib F, Bruley des Varannes S, Simon M, Galmiche JP. Functional heartburn: definition and management strategies. Curr Gastroenterol Rep. 2012;14(3):181-8. PMid:22451252. http://dx.doi.org/10.1007/s11894-0120255-7.

14. Farré R, Fornari F, Blondeau K, Vieth M, De Vos R, Bisschops R, et al. Acid and weakly acidic solutions impair mucosal integrity of distal exposed and proximal non-exposed human oesophagus. Gut. 2010;59(2):1649. PMid:19880965. http://dx.doi. org/10.1136/gut.2009.194191.

15. Giacchino M, Savarino V, Savarino E. Distinction between patients with nonerosive reflux disease and functional heartburn. Ann Gastroenterol. 2013;26(4):283-9. PMid:24714313.

Received: Dec 16, 2016 Accepted: Apr 30, 2017 